\title{
Accelerated Nursing Students: What Do They Believe Will Happen on the First Clinical Day
}

\author{
Sarah E. Newton, PhD, $\mathbf{R N}^{1}$ \\ Undergraduate Program Director, Oakland University School of Nursing \\ 3004 Human Health Building, Rochester, MI 48309
}

\begin{abstract}
Accelerated nursing (AN) programs have proliferated across the United States. Because AN curricula are taught at an accelerated pace, AN students tend to start their first clinical experiences early in the program, before they have received much formal education regarding what professional nursing is and what is expected of students in the clinical setting. The first clinical day has been described as stressful for nursing students (Wolf, Stidham, \& Ross, 2015), yet there was nothing found in the literature that described what AN students think will happen on the first clinical day or what will be expected of them. As a result, one Midwestern school of nursing conducted a quality improvement project to assess what the AN students thought would happen on the first clinical day. Specifically, the students were asked to "Describe what you think will happen on the first day of clinical". The results revealed four themes, but the majority of AN students thought they would be a "doer" and few reported the use of critical thinking or the application of newly learned nursing knowledge as something they would do on the first clinical day. Based on the project's findings, the implications for nurse educators who teach in AN curricula are discussed.
\end{abstract}

\section{INTRODUCTION}

Accelerated nursing (AN) programs have sprung up across the United States in recent years. AN programs offer the quickest route to licensure as a registered nurse for adults who already possess a bachelor's or graduate degree in a non-nursing discipline (American Association of Colleges of Nursing [AACN], 2014). While AN curricula are similar to traditional nursing program curricula, they are delivered over a shorter period of time (11-18 months) (AACN, 2014) at an accelerated pace. As a result, AN students usually begin the first clinical experience soon after they enter the program, when they have received little formal nursing education, and lack understanding of what it means to be a nursing student in the clinical setting. Because AN students have a multitude of educational backgrounds (e.g. basic science, health science, social science, and liberal arts/humanities) and do not necessarily have any experience in health care (Lyon, Younger, Goodloe, \& Ryland, 2010), it is important for nurse educators to know what AN students think will occur on the first clinical day and whether they have any misconceptions regarding their role as a student in an educational program preparing them to be a professional nurse. Lastly, and perhaps most importantly, a search of the literature revealed that the first day of clinical from the students' perspectives has not been the focus of much research, even though the literature indicates that a student nurse's first clinical experience is often viewed as stressful (Beck, 1993; Wolf, Stidham, \& Ross, 2015). As a result, one Midwestern school of nursing (SON) felt it was important to assess what their AN students thought would occur on the first day of clinical. A quality improvement project was undertaken that asked the first semester AN students to "Describe what you believe will happen on the first day of clinical".

\section{METHOD}

The project design was qualitative and descriptive. The participants were first semester AN students from one Midwestern state-supported SON. The quality improvement project was undertaken to help the SON understand what the AN students thought would occur on the first day of clinical so the SON could develop in-service programs for the SON faculty/clinical instructors who teach the first semester AN clinical courses. Participating students were ensured anonymity, were told not to write any identifying information on their responses, and that data would be reported only in aggregate.

To recruit participants for the project, the SON Dean visited a session of the AN curriculum's health assessment (HA) class that is taught during the first seven weeks of the first semester. The AN students' first clinical experiences, conducted on in-patient medical-surgical units at large urban hospitals, are held during the second

${ }^{1}$ Corresponding Author: newton@oakland.edu 
seven weeks of the first semester. The SON Dean explained the purpose of the project to the AN students and left a stack of paper in the HA laboratory that had the phrase, "Describe what you believe will happen on the first day of clinical. Please put your answer in the box in the main SON lab. NO NAMES PLEASE!" written at the top. The Dean placed a large sealed box with a narrow slit in its top in the main SON laboratory where students were instructed to submit their responses. Students were given until the end of the day to participate (approximately four hours). When the HA class concluded for the day, the instructor returned the sealed box to the Dean's office.

\section{RESULTS}

In total, $51 \mathrm{AN}$ students provided written responses (out of 58 in the cohort; 88\%). Each response was read by this author and the SON Dean in order to identify content areas that were present in the written text. Content areas were extracted from each response (from one to seven) and the content areas were then categorized into themes. The data revealed four themes: doer (active and passive), emotions, introductions, and critical thinker (Table 1). The theme "doer" was the most common ( $\mathrm{n}=106)$, whereas "critical thinker" was the least common $(\mathrm{n}=2)$.

Table1. Themes: What AN Students Think will Happen on the First Clinical Day

\begin{tabular}{|l|l|}
\hline Theme & Frequency \\
\hline Doer & 106 \\
\hline Active & 85 \\
\hline Pass medications & 2 \\
\hline Get report & 4 \\
\hline Document in the EHR & 11 \\
\hline Be assigned a patient(s) & 20 \\
\hline Do assessments/vital signs & 21 \\
\hline Do ADLs/tasks/'dirty work" & 27 \\
\hline Passive & 21 \\
\hline Review policies/procedures & 4 \\
\hline Observe/shadow a nurse & 17 \\
\hline Emotions & 29 \\
\hline Nervous/overwhelming & 17 \\
\hline Excited/Educational & 10 \\
\hline No preconceptions & 2 \\
\hline Introductions & 31 \\
\hline To instructor/clinical & 9 \\
\hline To hospital/nursing unit/nurses & 22 \\
\hline Critical Thinker & 2 \\
\hline
\end{tabular}

\section{DISCUSSION}

The results revealed that newly admitted AN students thought the first clinical day would be focused on doing, both passive and active, but that their primary role would be to "do" (e.g. perform assessments, take patients' vital signs, and provide basic patient care). The AN students' written descriptions also revealed that they expected to feel nervous and/or excited, and that introductions (to the hospital, to the nursing unit, and to the nurses on the unit where they were assigned) would be an important part of the first day. In contrast, only two AN students described critical thinking and/or the application of nursing knowledge as something that would occur on the first clinical day.

\section{IMPLICATIONS}

The findings of this project have several implications for nurse educators who teach in AN programs. In the 21st century, the preparation of professional nurses requires an educational approach that encourages critical, creative thinking, and less reliance on the nurse as the doer of "tasks" (Benner, Sutphen, Leonard, \& Day, 2010; McCallaGraham \& De Gagne, 2015). The education AN students receive in the classroom promotes such knowledge-based competencies, yet this project's findings indicate that many AN students do not believe they will be expected to demonstrate them on the first clinical day. As Benner et al. (2010) wrote, "The student's lay visions of nursing before entering nursing school are often far off the mark ..." (p. 42). 
Student nurses throughout their educational experiences engage in ongoing identity construction and deconstruction (Johnson, Cowin, Wilson, \& Young, 2012). "This occurs through teachers and mentors in nursing, and the integration of information relating the professional values, attributes, gaining knowledge about health systems, the study of human physiology and pathophysiology, and the skills and competencies required by persons within the profession" (Johnson et al., 2012, p. 564). Because the typical AN student has been described as motivated, older, and has higher academic expectations than traditional entry-level nursing students (AACN, 2014), then in order for them to be able to develop a professional identity that includes more than being a doer of "tasks", nurse educators must strive for deeper, more effective integration of knowledge, and a "shift from a focus on covering decontextualized knowledge to an emphasis on teaching for a sense of salience..." (Benner et al., 2010, p. 82). The AN students, who for the most part, are eager to gain clinical experiences (AACN, 2014), need a nursing education that is embedded with a deeper sense of salience that will allow them to understand nursing as a professional discipline that values critical thinking and the effective use of knowledge, especially during clinical nursing practice. However, because nursing demands both a depth and breadth of knowledge, and because AN students are given a lot of information in a very short period of time, there is also the need for nurse educators to re-envision the teaching role and re-construct pedagogy that use the students' time and prior knowledge more effectively (Benner et al., 2010).

Unfortunately, the findings of this project are limited because they do not explain whether the AN students' written descriptions regarding what they think will occur on the first clinical day compare to what actually occurred on the first day and/or how the students' pre-clinical beliefs affected their performance during their first clinical experience. With little found in the literature on this topic, it is clear that more research is needed, especially research that facilitates a better understanding of the AN students' beliefs regarding professional nursing and what is expected of them in their role as a professional nursing student, and ultimately whether their beliefs impact their academic progression in the AN curriculum.

\section{CONCLUSION}

In conclusion, the results of this quality improvement project indicate that AN students believe that much of the first clinical day will focus on doing basic "tasks", a conceptualization of the nursing role that is not consistent with the current view of nurses as knowledge users (Benner et al., 2010). In order for AN students to understand what their role will be on the first clinical day, they need a nursing education that is embedded with a sense of salience, that promotes "thinking like a nurse" (Benner et al., 2010, p. 85), and that is based on the realities of contemporary nursing practice.

\section{REFERENCES}

[1] American Association of Colleges of Nursing. (2015). Accelerated nursing programs. Retrieved from: http://www.aacn.nche. edu/students/accelerated-nursing-programs

[2] Beck, C. T. (1993). Nursing students' initial clinical experience: A phenomenological study. International Journal of Nursing Studies, 30(6), 489-497.

[3] Benner, P., Sutphen, M., Leonard, V., \& Day, L. (2010). Educating nurses: A call for radical transformation. San Francisco, CA: Jossey-Bass.

[4] Johnson, M., Cowin, L. S., Wilson, I., \& Young, H. (2012). Professional identity and nursing: Contemporary theoretical developments and future research challenges. International Nursing Review, 59, 562-569. doi: 10.1111/j.14667657.2012.01013.x

[5] Lyon, D., Younger, J., Goodloe, L., \& Ryland, K. (2010). Nursing students' perceptions of how their prior educational foci and work experience affected their transition into an accelerated nursing program. Southern Online Journal of Nursing Research, 10(1). Retrieved from: http://www.resourcenter.net/images/snrs/files/sojnr_articles2/Vol10Num01Art11.pdf

[6] McCalla-Graham, J. A., \& De Gagne, J. C. (2015). The lived experience of new graduate nurses working in an acute care setting. The Journal of Continuing Education in Nursing, 46(3), 122-128. doi:10.3928/00220124-20150220-17

[7] Wolf, L., Stidham, A. W., \& Ross, R. (2015). Predictors of stress and coping strategies of US accelerated vs. generic baccalaureate nursing students: An embedded mixed methods study. Nurse Education Today, 35(1), 201-205. doi:10.1016/j.nedt.2014.07.005. 